\title{
ASTHMA
}

\section{Effect of montelukast added to inhaled budesonide on control of mild to moderate asthma}

\author{
M J Vaquerizo, P Casan, J Castillo, M Perpiña, J Sanchis, V Sobradillo, A Valencia, \\ H Verea, J L Viejo, C Villasante, J Gonzalez-Esteban, C Picado, for the CASIOPEA \\ (CApacidad de SIngulair Oral en la Prevencion de Exacerbaciones Asmaticas) Study \\ Group*
}

See end of article for authors' affiliations ........................

Correspondence to: Dr M J Vaquerizo, Merck Sharp \& Dohme, c/ Josefa Valcarcel 38, 28027

Madrid, Spain;

maria_jose_vaquerizo@ merck.com

Revised version received 30 October 2002 Accepted for publication 18 November 2002

\begin{abstract}
Background: Proinflammatory leukotrienes, which are completely inhibited by inhaled corticosteroids, may contribute to asthmatic problems. A 16 week multicentre, randomised, double blind, controlled study was undertaken to study the efficacy of adding oral montelukast, a leukotriene receptor antagonist, to a constant dose of inhaled budesonide.

Methods: A total of 639 patients aged 18-70 years with forced expiratory volume in 1 second $\left(\mathrm{FEV}_{1}\right)$ $\geqslant 55 \%$ predicted and a minimum predefined level of asthma symptoms during a 2 week placebo run in period were randomised to receive montelukast $10 \mathrm{mg}(n=326)$ or placebo $(n=313)$ once daily for 16 weeks. All patients received a constant dose of budesonide (400-1600 $\mu \mathrm{g} /$ day) by Turbuhaler throughout the study.

Results: Mean FEV, at baseline was $81 \%$ predicted. The median percentage of asthma exacerbation days was $35 \%$ lower $(3.1 \% \vee 4.8 \% ; \mathrm{p}=0.03)$ and the median percentage of asthma free days was $56 \%$ higher $(66.1 \% \vee 42.3 \% ; p=0.001)$ in the montelukast group than in the placebo group. Patients receiving concomitant treatment with montelukast had significantly $(p<0.05)$ fewer nocturnal awakenings and significantly $(p<0.05)$ greater improvements in $\beta$ agonist use and morning peak expiratory flow rate (PEFR).

Conclusions: For patients with mild airway obstruction and persistent asthma symptoms despite budesonide treatment, concomitant treatment with montelukast significantly improves asthma control.
\end{abstract}

t nhaled corticosteroids are considered one of the first line treatments for patients with persistent asthma. ${ }^{2}$ These agents have proven efficacy in asthma, improving lung function and reducing asthma exacerbations, and their anti-inflammatory effects in the lungs are well established. ${ }^{3-5}$ Nonetheless, many patients receiving inhaled corticosteroids continue to experience asthma symptoms, possibly because corticosteroids do not completely inhibit the synthesis and release of cysteinyl leukotrienes in the lungs. ${ }^{67}$

The cysteinyl leukotrienes LTC4, LTD4, and LTE4 induce many of the pathophysiological changes present in the lungs of patients with asthma, including airflow obstruction, mucus secretion, reduced mucociliary clearance, and inflammatory cell infiltration. ${ }^{89}$ Antileukotriene drugs prevent provoked asthmatic responses and ameliorate asthma symptoms, improve lung function, and reduce $\beta$ agonist use in patients with persistent asthma. ${ }^{10}$ Montelukast, a cysteinyl leukotriene type 1 (CysLTl) receptor antagonist, has been found to reduce airway eosinophilic inflammation in patients with chronic asthma. ${ }^{11}$

The anti-inflammatory effects of inhaled corticosteroids and montelukast may be complementary, as shown in previous studies in adults ${ }^{12}$ and children. ${ }^{13}$ These studies used lung function improvements as the predefined primary end point; there are no published studies of montelukast using reductions in asthma exacerbations as a primary end point, and this is a prominent goal of asthma treatment in national and international guidelines. ${ }^{12}$

The purpose of this 16 week randomised controlled study was to evaluate the efficacy of adding oral montelukast to a

*A complete list of members of the CASIOPEA Study Group is provided in the Appendix. constant dose of inhaled budesonide for treating adult patients with mild to moderate asthma. Our hypothesis was that montelukast treatment would provide additional benefit and be safe and well tolerated for symptomatic asthmatic patients receiving inhaled budesonide, as measured by a reduction in the percentage of days of asthma exacerbations.

\section{METHODS}

Study design

This placebo controlled, randomised, parallel group study, conducted at 80 hospital centers in Spain, comprised a 2 week single blind placebo run in period and a 16 week double blind treatment period. Throughout the study all patients received a constant dosage of inhaled budesonide (Budesonide Turbuhaler, Astra, Lund, Sweden; 400-1600 $\mu \mathrm{g} /$ day administered twice daily). After the 2 week run in period, patients were randomly assigned, according to a central computer generated schedule, to receive concomitant montelukast $10 \mathrm{mg}$ film coated tablets or matching placebo once daily at bedtime, irrespective of food. Treatment assignments (1:1) were stratified according to site and three budesonide dose levels (400$800 \mu \mathrm{g} / \mathrm{day}, 80 \mathrm{l}-1200 \mu \mathrm{g} / \mathrm{day}$, and 1201-1600 $\mu \mathrm{g} /$ day). Participants, investigators, clinical monitors, and data coordinators were all blinded to treatment assignment. Patients used an inhaled short acting $\beta$ agonist (salbutamol) as needed. The use of systemic corticosteroids, long acting antihistamines, and other antiasthmatic medications was not permitted.

\section{Patients}

Patients enrolled in the study were non-smoking male and female asthmatic outpatients aged 18-70 years who had been treated with inhaled corticosteroids at a clinically stable dose equivalent to budesonide $400-1600 \mu \mathrm{g} /$ day for at least 8 
weeks. Eligible patients had a forced expiratory volume ( $\left.\mathrm{FEV}_{1}\right)$ of at least $55 \%$ of the predicted value and evidence of reversible airway obstruction (increase of at least $12 \%$ in $\mathrm{FEV}_{1}$ from the baseline value). During the 2 week run in period patients were required to have a minimum total daytime asthma symptom score of 64 (out of a possible maximum score in 14 days of 336) in addition to using a mean of at least 1 puff/day of $\beta$ agonist. Women of childbearing age were required to have a negative pregnancy test (urine $\beta$-human chorionic gonadotropin) at screening and to use an appropriate contraceptive from 2 weeks before treatment until 14 days after the end of the study.

The study protocol was approved by each local ethical committee and all participants gave written informed consent.

\section{Evaluations}

All patients were issued a validated diary card for recording daily daytime asthma symptom scores, nocturnal awakenings, study medication use including as needed $\beta$ agonist, morning and evening peak expiratory flow rate (PEFR), and the occurrence of asthma attacks. Daytime symptoms were evaluated each night before bed, and night time symptoms were evaluated in the morning on rising using validated measurement scales. ${ }^{14}$

Spirometric tests were performed at screening, at randomisation, and on completion of the study according to standardised procedures. ${ }^{15}{ }^{16}$ Asthma specific quality of life was assessed before randomisation and at the end of the 16th week of treatment or on discontinuation of the study using a validated questionnaire containing 32 questions graded from 0 (worst response) to 6 (best response), evenly divided among four domains (activity, symptoms, emotions, and environment $)^{17}$; the mean numerical response was calculated for each domain and for all domains. At the end of treatment patients and investigators also rated global asthma status relative to that on entering the study using a 7 point scale ranging from 0 (very much better) to 3 (unchanged) to 6 (very much worse).

Safety evaluations included adverse event reporting, physical examinations, 12 lead electrocardiograms, recording of vital signs, and clinical laboratory testing. The pregnancy test was repeated before randomisation and at the end of the study for women of childbearing age.

\section{Statistical methods}

All analyses were performed for the intention-to-treat patient population that included all randomised patients who had a baseline and at least one post-treatment assessment. The prespecified primary efficacy end point was the percentage of asthma exacerbation days, defined by Laviolette et $\mathrm{al}^{12}$ as days when any of the following occurred: awake all night (awake all night or recurrent episodes of awakening), increase from baseline in symptom score of $>50 \%$, increase from baseline in $\beta$ agonist use of $>70 \%$ (minimum increase 2 puffs/day), decrease from baseline of $>20 \%$ in morning PEFR, morning PEFR $<180 \mathrm{l} / \mathrm{min}$, or an asthma attack (unscheduled medical care for asthma). Post hoc analyses were performed using two alternative definitions of an asthma exacerbation day, the first similar to that outlined by Wilding and coworkers ${ }^{18}$ and by Chan-Yeung and coworkers ${ }^{19}$-namely, a day when any of the following occurred: an asthma attack or, on two consecutive days, nocturnal waking, increase from baseline of more than $50 \%$ in symptoms score, use of at least 4 puffs/day of $\beta$ agonist, decrease from baseline of more than $30 \%$ or more than $100 \mathrm{l} /$ min in PEFR, or daily variability of more than $20 \%$ in PEFR. The second definition of an asthma exacerbation day was similar to that used by Pauwels et al for a mild exacerbation ${ }^{20}-$ namely, a day when any of the following occurred: decrease from baseline of more than $20 \%$ in morning PEFR, increase from baseline in $\beta$ agonist use of at least 3 puffs, or nocturnal waking because of asthma (single isolated days of exacerbations were not counted using this definition).

A secondary end point was the number of asthma free days, defined as a day when all of the following occurred: no nocturnal waking, use of two puffs or less of $\beta$ agonist, no use of oral corticosteroids, and no unscheduled use of medical care for asthma. Other prespecified secondary end points were the daily use of $\beta$ agonist and asthma specific quality of life. Tertiary end points were as follows: morning PEFR, daytime symptom score, discontinuations secondary to asthma, $\mathrm{FEV}_{1}$, and patient and physician global evaluations.

All patients, investigators, clinical monitors, and data coordinators were blinded throughout the study to the outcome measures of asthma exacerbation days and asthma free days. The percentages of asthma exacerbation days and asthma free days were non-normally distributed so the median and 95\% confidence intervals (CI), calculated according to the method of Gardner and Altman, ${ }^{21}$ were used as the central measurement of data in both groups. The two sample median test attributed to $\operatorname{Mood}^{22}$ and the corresponding distribution-free CI for the difference between the two treatment groups were used to assess the treatment effect by non-parametric methods. The Breslow-Day test ${ }^{23}$ was used to assess the homogeneity of the treatment levels. The proportions of asthma exacerbation days and of asthma free days were calculated from the total number of follow up days in each treatment group. From these proportions the absolute risk reduction, relative risk, reduction in relative risk, and corresponding 95\% CI were also calculated using the Wald method. ${ }^{23}$ The reciprocal of the absolute risk reduction-namely, the number needed to treat (NNT) - was then obtained for each end point (asthma exacerbation and asthma free days). The NNT is thus defined as the number of treatment days with montelukast needed to prevent either an asthma exacerbation day or a non-asthma free day (to gain an asthma free day).

For those efficacy end points with a baseline value, the mean changes from baseline and 95\% CI during 16 weeks of treatment were computed. An analysis of variance (ANOVA) model containing terms for treatment, study centre, and dose of inhaled budesonide was used to evaluate between group differences and to construct the 95\% CI for the least square (LS) means and the differences in LS means. The frequency of discontinuation secondary to asthma was compared between treatment groups using Fisher's exact test. Patient and physician global evaluations were analysed using the ANOVA model and by reducing the 7 point scales into three categories of better (score of 0-3), unchanged (4), and worse (5-7). The proportion of patients in each category according to treatment group was summarised and tested using the Cochran-MantelHaenszel test, controlling for dose level where applicable.

Summary statistics were calculated for baseline characteristics of the two treatment groups, as well as for changes from baseline in laboratory values and vital signs. Adverse experiences were collected according to frequency of occurrence and the proportion of patients having any adverse experience was compared between treatment groups using Fisher's exact test.

Prestudy power calculations yielded a sample size of 546 patients, equally divided between placebo and montelukast treatment groups, to have $90 \%$ power (at $\alpha=0.05$, two sided test) to detect a 5\% difference, assuming a standard deviation of $18 \%$ between treatment groups in the percentage of asthma exacerbation days.

\section{RESULTS}

\section{Patients}

Of 846 patients evaluated for inclusion in the study, 639 (76\%) were randomly assigned to receive double blind treatment (fig 1). Of these 639 randomised patients, 573 (90\%) completed the 16 week follow up planned for the study. Reasons for not 


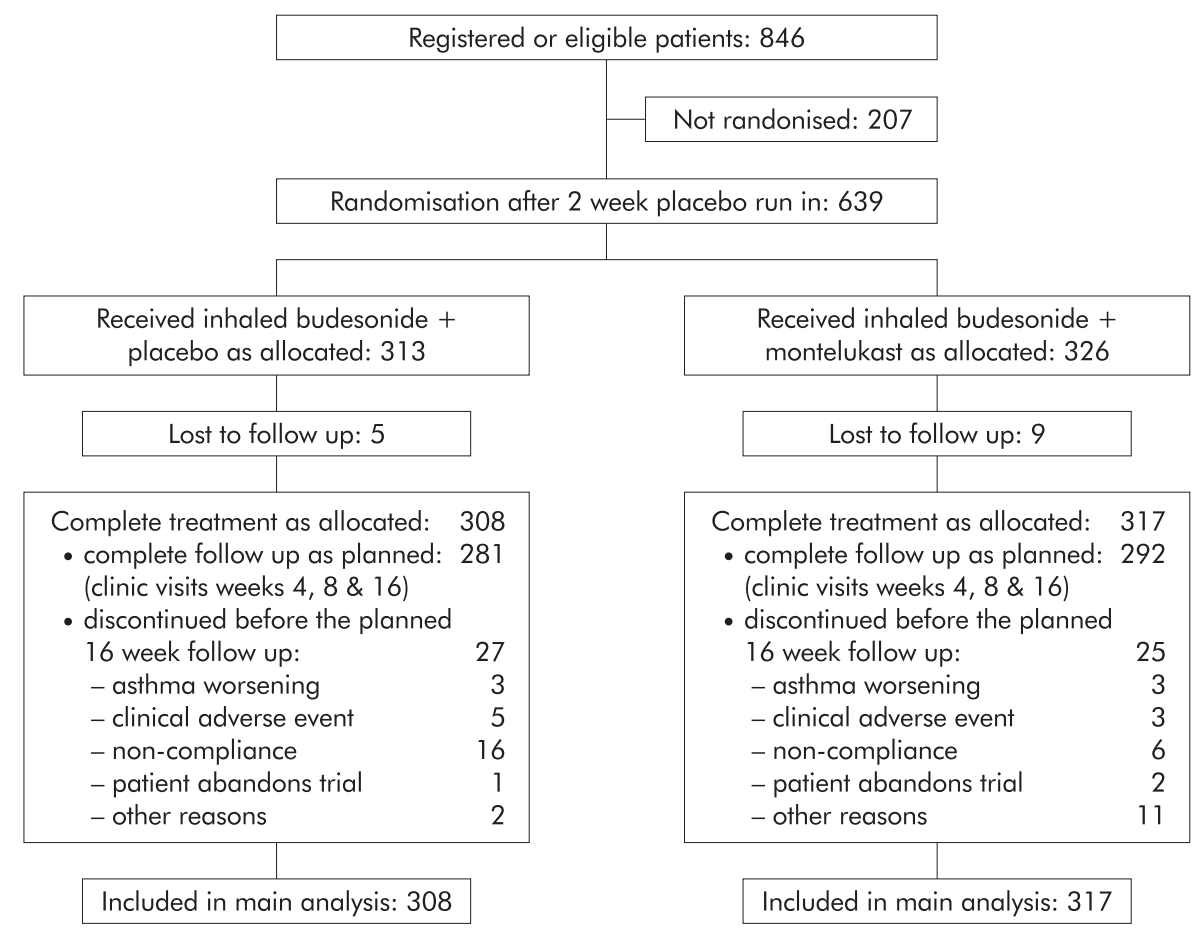

Figure 1 Flow chart of study patients. Of the 207 patients who were not randomised, 63 deviated from the protocol, 38 experienced an adverse clinical event, 24 were not cooperative, five were lost to follow up, three did not have case report forms, one experienced an adverse laboratory event, and 73 were not randomised for other reasons.

randomising patients and for discontinuing patients before the planned 16 week follow up are shown in fig l. Primary end point data were available for $98 \%$ of randomised patients, including 308 of $313(98 \%)$ in the placebo group and 317 of $326(97 \%)$ in the montelukast group.

Mean baseline characteristics were similar for randomised and non-randomised patients. For randomised patients, mean baseline characteristics were comparable for the two treatment groups (table 1). Approximately two thirds of patients in each treatment group received the lowest dose of budesonide $(400-800 \mu \mathrm{g} /$ day) and almost one third received the highest dose (1201-1600 $\mu \mathrm{g} /$ day). The mean baseline $\mathrm{FEV}_{1}$ was $81 \%$ predicted in both treatment groups.

\section{Efficacy}

Treatment with montelukast produced a significant reduction of $35 \%$ in the percentage of asthma exacerbation days compared with placebo in patients receiving concomitant budesonide (table 2). These results were independent of the budesonide dose level $(\mathrm{p}=0.67)$.

Our findings were consistent in post hoc analyses using the two alternative definitions, with reductions of 37\% (first definition) and 32\% (second definition) in the percentages of exacerbation days in the montelukast group compared with the placebo group $(\mathrm{p}=0.05$ and $\mathrm{p}=0.07$, respectively). Using the first definition, ${ }^{18}{ }^{19}$ the median percentage of asthma exacerbation days during treatment was $13.4 \%$ (95\% CI 9.9 to 18.0 ) in the montelukast group and $21.1 \%$ (95\% CI 15.7 to 28.2 ) in the placebo group. With the second definition ${ }^{20}$ the median percentage of asthma exacerbation days during treatment was $8.9 \%$ (95\% CI 6.3 to 12.2 ) in the montelukast group and $13.0 \%$ (95\% CI 9.7 to 18.2 ) in the placebo group.

The median percentage of asthma free days was $56 \%$ higher in the montelukast group than in the placebo group $(p=0.001$; fig 2, table 2). These results were also independent of the budesonide dose level $(p=0.70)$.

The risk of an asthma exacerbation day or a "day not free of asthma" was lower in patients receiving montelukast than in those receiving placebo. Montelukast treated patients had a

\begin{tabular}{|c|c|c|}
\hline Characteristic & $\begin{array}{l}\text { Placebo } \\
(n=313)\end{array}$ & $\begin{array}{l}\text { Montelukast } \\
10 \mathrm{mg} \\
(\mathrm{n}=326)\end{array}$ \\
\hline Mean (SD) age (years) & $44(16)$ & $42(15)$ \\
\hline Range & $18-79$ & $18-76$ \\
\hline \multicolumn{3}{|l|}{ Sex, n (\%): } \\
\hline Female & $121(39 \%)$ & $124(38 \%)$ \\
\hline Male & $192(61 \%)$ & $202(62 \%)$ \\
\hline Mean (SD) BMI & $27.0(4.4)$ & $26.8(4.6)$ \\
\hline Ex-smokers (\%) & $30 \%$ & $37 \%$ \\
\hline Mean (SD) duration of asthma (years) & $13.8(11.7)$ & $13.8(11.4)$ \\
\hline Mean (SD) FEV 1 (I) & $2.5(1.0)$ & $2.5(0.9)$ \\
\hline Mean (SD) FEV $1 \%$ predicted) & $81(21)$ & 81 (19) \\
\hline \multicolumn{3}{|l|}{ Budesonide dose level, ${ }^{*} \mathrm{n}(\%)$} \\
\hline $400-800 \mu g /$ day & $202(66 \%)$ & $219(69 \%)$ \\
\hline $801-1200 \mu g /$ day & $15(5 \%)$ & $18(6 \%)$ \\
\hline $1201-1600 \mu g /$ day & $91(30 \%)$ & $80(25 \%)$ \\
\hline $\begin{array}{l}\text { Mean (SD) daytime asthma symptom } \\
\text { score } \dagger\end{array}$ & $2.3(0.8)$ & $2.2(0.8)$ \\
\hline Mean (SD) $\beta$ agonist use (puffs/day) & $3.3(2.3)$ & $3.2(2.5)$ \\
\hline Mean (SD) morning PEFR (l/min) & $365(108)$ & $373(105)$ \\
\hline Mean (SD) evening PEFR (I/min) & 375 (108) & $382(107)$ \\
\hline
\end{tabular}

$\mathrm{BMI}=$ body mass index; $\mathrm{FEV}_{1}=$ forced expiratory volume in 1 second; PEFR=peak expiratory flow rate.

All patients were also receiving inhaled budesonide by Turbuhaler $400-1600 \mu \mathrm{g} /$ day.

*Forty four $(14 \%)$ and $35(1 \%)$ patients in the placebo and montelukast groups, respectively, received $400 \mathrm{\mu g} /$ day.

tDaytime asthma symptom score was the mean of scores to four questions, each rated on a scale from 0 (best) to 6 (worst). ${ }^{14}$

total of 9802 exacerbation days and 16281 days not free of asthma out of 36088 treatment days whereas the placebo treated patients had 11930 exacerbation days and 18884 days not free of asthma out of 34318 treatment days. Patients treated with montelukast therefore had a relative risk (RR) of an asthma exacerbation day of 0.78 (95\% CI 0.76 to 0.80$)$ and an RR of a day not free of asthma of 0.82 (95\% CI 0.81 to 0.83 ). 
Table 2 Results for efficacy end points without baseline values

\begin{tabular}{|c|c|c|c|c|}
\hline End point & Placebo $(n=308)$ & Montelukast $10 \mathrm{mg}(n=317)$ & Effect difference & p value* \\
\hline Median (95\% CI) asthma exacerbation days (\%) & $4.8 \%(3.5$ to 6.3$)$ & $3.1 \%(2.0$ to 4.2$)$ & $1.7 \%(1.2$ to 6.3$)$ & 0.03 \\
\hline Median $(95 \% \mathrm{CI})$ asthma free days $(\%)$ & $42.3 \%(32.7$ to 51.2$)$ & $66.1 \%(57.4$ to 73.8$)$ & $23.8 \%(10.9$ to 41.2$)$ & 0.001 \\
\hline LS mean $(95 \% \mathrm{CI})$ nocturnal awakenings (\%) & $32.2 \%(25.9$ to 38.5$)$ & $25.6 \%(19.3$ to 31.9$)$ & $6.6 \%(1.9$ to 13.7$)$ & 0.01 \\
\hline Discontinuation because of asthma, $\mathrm{n}(\%)$ & $3(1 \%)$ & $3(1 \%)$ & $0 \%$ & 1.00 \\
\hline
\end{tabular}

All patients were also receiving inhaled budesonide by Turbuhaler $400-1600 \mu \mathrm{g} /$ day.

${ }^{*} \mathrm{p}$ value is for the montelukast $v$ placebo.

Nocturnal awakenings represent the percentage of patients who awoke during the night because of asthma.

$\mathrm{LS}=$ least square.

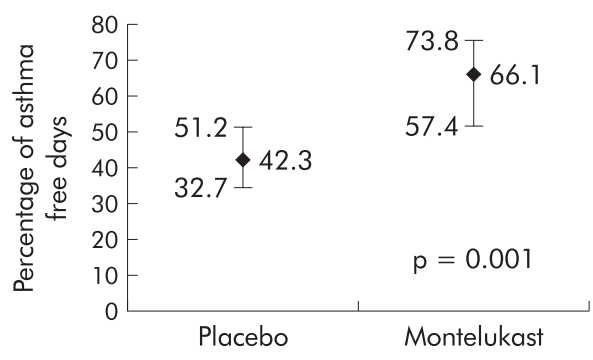

Figure 2 Median percentage $(95 \% \mathrm{Cl})$ of asthma free days during 16 weeks of treatment with inhaled budesonide plus concomitant once daily placebo or montelukast in patients with mild to moderate asthma. The percentage of asthma free days was significantly higher in patients receiving montelukast than in those receiving placebo $(p=0.001)$.

The relative reduction in risk (RRR) of an asthma exacerbation day was $21.9 \%$ (95\% CI 20.1 to 23.6 ) for patients receiving montelukast. Similarly, the RRR for a "day not free of asthma" was $18.0 \%$ (95\% CI 16.8 to 19.2 ) for patients receiving montelukast. The number of days needed to treat (NNT) with montelukast to avoid one exacerbation day was 13, and the NNT to avoid one day not free of asthma-that is, to gain an asthma free day-was 10.

The results for other end points are summarised in tables 2 and 3. Patients receiving concomitant treatment with montelukast had significantly fewer nocturnal awakenings and showed significantly greater improvements in $\beta$ agonist use and morning PEFR. The effect of montelukast on $\beta$ agonist use was evident within the first day of treatment. The decrease from baseline in $\beta$ agonist use was significantly lower in the montelukast group on the first day compared with the placebo group ( $p=0.04$, fig 3 ) and remained consistent over the 16 weeks of treatment.

Improvements in daytime asthma symptom scores (fig 4), asthma specific quality of life scores, and $\mathrm{FEV}_{1}$ were numerically greater in the montelukast group but did not reach statistical significance compared with improvements in the placebo group (table 3 ). Only six patients (three in each group) discontinued treatment because of worsening asthma.

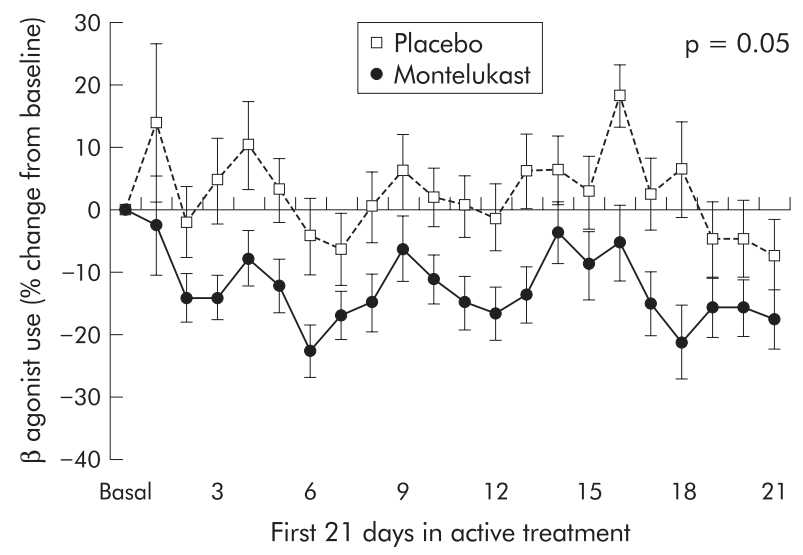

Figure 3 Mean percentage change from baseline in use of rescue $\beta$ agonist treatment during the first 21 days of treatment with placebo or montelukast in patients receiving inhaled budesonide (mean adjusted according to treatment centre and dose level).

Results for the global evaluations were similar for the two treatment groups. Asthma status was rated as better during the study by $83-84 \%$ of patients in both groups, $12 \%$ rated it unchanged, and $4-5 \%$ rated it worse. Seventy six percent of physicians rated the patient's asthma as better, 19\% as unchanged, and $5 \%$ as worse for both treatment groups.

\section{Safety}

The overall incidence of adverse experiences was similar in the two treatment groups (table 4). Raised transaminase levels ( $>2$ times above the upper limit of normal) occurred in a similar proportion of patients in both groups. Eight patients in the placebo group and six in the montelukast group discontinued treatment because of clinical adverse events (three in each group because of worsening asthma). No patient withdrew from the study because of laboratory adverse events.

\section{DISCUSSION}

The addition of montelukast to budesonide Turbuhaler (400$1600 \mu \mathrm{g} /$ day) improved asthma control for symptomatic

Table 3 Change from baseline in efficacy end points

\begin{tabular}{|c|c|c|c|c|}
\hline End point & Placebo $(n=308)$ & Montelukast $10 \mathrm{mg}(\mathrm{n}=317)$ & Effect difference & p value* \\
\hline LS mean (SE) rescue $\beta$ agonist use (\%) & $\begin{array}{l}-4.92(7.56) \\
(95 \% \mathrm{Cl}-19.76 \text { to } 9.93)\end{array}$ & $\begin{array}{l}-17.26(7.50) \\
(95 \% \mathrm{Cl}-31.99 \text { to }-2.53)\end{array}$ & $\begin{array}{l}-12.34(6.24) \\
(95 \% \mathrm{Cl}-0.11 \text { to }-24.57)\end{array}$ & 0.05 \\
\hline LS mean (SE) morning PEFR (I/min) & $\begin{array}{l}11.30(3.45) \\
(95 \% \mathrm{Cl} 4.53 \text { to } 18.08)\end{array}$ & $\begin{array}{l}16.86(3.41) \\
(95 \% \mathrm{Cl} 10.15 \text { to } 23.55)\end{array}$ & $\begin{array}{l}5.55(2.86) \\
(95 \% \mathrm{Cl}-0.06 \text { to } 11.16)\end{array}$ & 0.05 \\
\hline LS mean (SE) daytime asthma symptom score & $\begin{array}{l}-0.24(0.06) \\
(95 \% \mathrm{Cl}-0.37 \text { to }-0.12)\end{array}$ & $\begin{array}{l}-0.34(0.06) \\
(95 \% \mathrm{Cl}-0.46 \text { to }-0.22)\end{array}$ & $\begin{array}{l}-0.09(0.05) \\
(95 \% \mathrm{Cl}-0.19 \text { to } 0.01)\end{array}$ & 0.07 \\
\hline Mean (SE) asthma specific quality of life score & $0.52(0.05)$ & $0.60(0.05)$ & $-0.08(0.07)$ & 0.34 \\
\hline LS mean (SE) morning $\mathrm{FEV}_{1}(\%)$ & $\begin{array}{l}2.49(1.63) \\
(95 \% \mathrm{Cl}-0.71 \text { to } 5.69)\end{array}$ & $\begin{array}{l}2.63(1.62) \\
(95 \% \mathrm{Cl}-0.55 \text { to } 5.81)\end{array}$ & $\begin{array}{l}0.14(1.33) \\
(95 \% \mathrm{Cl}-2.47 \text { to } 2.75)\end{array}$ & 0.91 \\
\hline
\end{tabular}

All patients were also receiving inhaled budesonide by Turbuhaler $400-1600 \mu \mathrm{g} /$ day.

* $p$ value is for the montelukast $v$ placebo.

$\mathrm{FEV}_{1}=$ forced expiratory volume in 1 second; $\mathrm{LS}=$ least square; PEFR=peak expiratory flow rate. 


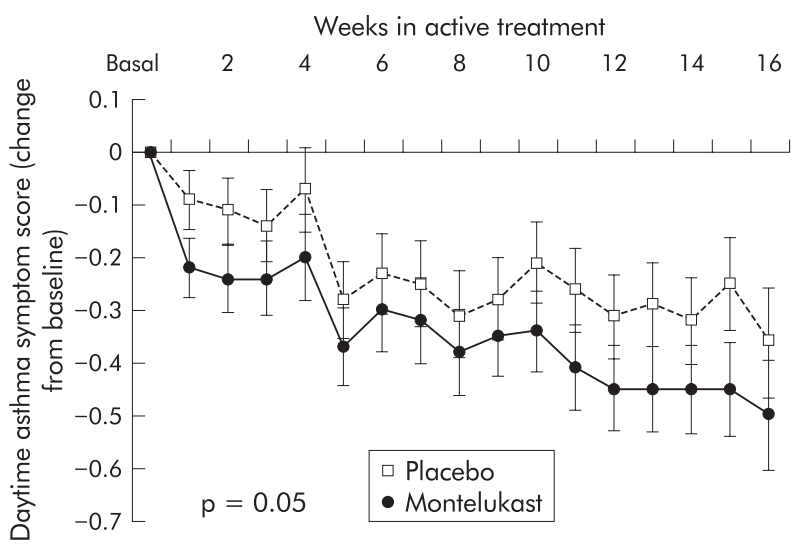

Figure 4 Mean change from baseline in daytime asthma symptom scores during 16 weeks of treatment with placebo or montelukast in patients receiving inhaled budesonide (mean adjusted according to treatment centre and dose level).

\begin{tabular}{|c|c|c|c|c|c|}
\hline \multirow[b]{2}{*}{ Adverse event } & \multicolumn{2}{|c|}{$\begin{array}{l}\text { Placebo } \\
(n=308)\end{array}$} & \multicolumn{2}{|c|}{$\begin{array}{l}\text { Montelukast } \\
10 \mathrm{mg} \\
(\mathrm{n}=317)\end{array}$} & \multirow[b]{2}{*}{$\mathrm{p}$ value* } \\
\hline & $\mathrm{n}$ & $\%$ & $\mathrm{n}$ & $\%$ & \\
\hline Influenza & 34 & 11.04 & 38 & 11.99 & 0.71 \\
\hline Headache & 29 & 9.42 & 34 & 10.73 & 0.59 \\
\hline Upper respiratory infection & 21 & 6.82 & 17 & 5.36 & 0.45 \\
\hline Worsening asthma & 15 & 4.87 & 22 & 6.94 & 0.27 \\
\hline Epigastric pain/pyrosis & 6 & 1.95 & 8 & 2.52 & 0.63 \\
\hline Urinary tract infection & 7 & 2.27 & 6 & 1.89 & 0.74 \\
\hline Rhinitis & 6 & 1.95 & 5 & 1.58 & 0.72 \\
\hline Pharyngitis & 4 & 1.30 & 5 & 1.58 & 0.77 \\
\hline Bronchitis & 3 & 0.97 & 5 & 1.58 & 0.24 \\
\hline Total & 125 & 40.58 & 140 & 44.16 & 0.37 \\
\hline
\end{tabular}

${ }^{*} \mathrm{p}$ value for montelukast $v$ placebo.

patients with mild to moderate asthma, as measured by the significantly lower percentage of asthma exacerbation days compared with the placebo group during the 16 week study. Patients receiving concomitant montelukast experienced a decrease of $35 \%$ in asthma exacerbation days and a $56 \%$ increase in the percentage of asthma free days compared with those receiving placebo. Moreover, the need for $\beta$ agonist reliever therapy, nocturnal awakenings, morning PEFR, and daytime asthma symptoms showed improvements in the montelukast treated patients. These improvements occurred despite the fact that patients had a mean baseline FEV of $81 \%$ predicted, indicating that patients receiving treatment with inhaled corticosteroids and with an $\mathrm{FEV}_{1}$ close to normal who remain symptomatic may need further control of asthmatic inflammation because of a lack of effect of inhaled corticosteroids on leukotrienes. ${ }^{67}$ Our findings suggest that the increase in asthma free days and the decrease in asthma exacerbation days with concomitant montelukast therapy can better detect improvements in control of asthmatic inflammation and thus may be a more sensitive clinical measure of inflammation control than changes in $\mathrm{FEV}_{1}$.

To understand better the clinical meaning of these results, we expressed our data in terms of the number of days needed to treat with montelukast to prevent one asthma exacerbation day or to gain one asthma free day. Our results showed that the addition of montelukast to budesonide in patients with mild to moderate asthma prevented one asthma exacerbation day and provided one asthma free day every 13 and 10 consecutive days of treatment, respectively.
This is the first published study of montelukast to use asthma exacerbation days as the primary end point. Asthma exacerbation days and asthma free days are clinically relevant end points that reflect the extent of asthma control experienced by patients on a daily basis, as well as the goals of asthma treatment according to national and international consensus guidelines. ${ }^{12}$ According to these guidelines, asthma treatment should aim to reduce or eliminate chronic symptoms and asthma exacerbations, minimise the need for $\beta$ agonist reliever therapy, permit normal activity levels, and maintain nearly normal lung function. Our definition of an asthma free day corresponds to the guideline goals of treatment and is similar to that of the episode free day proposed by Sculpher and Buxton ${ }^{24}$-namely, a day when there is an absence of asthma attacks, need for rescue medication, sleep disturbance caused by asthma, or an adverse event. With regard to the definition of an asthma exacerbation day, several definitions have been published in the literature which differ from one another, making it difficult to compare the results from different studies using this end point. We tested our findings with post hoc analyses using two alternative definitions of asthma exacerbation days and found the effects of montelukast treatment to be consistent under the different definitions, with reductions in exacerbation days of $37 \%$ and $32 \%$, respectively, compared with placebo. ${ }^{18-20}$

Patients received a constant dose of inhaled corticosteroids for at least 8 weeks before enrollment in the study and the same constant dose of inhaled budesonide during the 18 week study period. Patients were on different constant doses of inhaled budesonide (400-800 $\mu \mathrm{g} /$ day, $801-1200 \mu \mathrm{g} / \mathrm{day}$, and $1201-1600 \mu \mathrm{g} /$ day) and the mean baseline $\mathrm{FEV}_{1}$ was $81 \%$ predicted. The efficacy of concomitant montelukast was evident at both low and high budesonide doses, as improvements in asthma exacerbation days and asthma free days were independent of budesonide dose.

Other studies have shown the complementary activity of antileukotrienes with inhaled corticosteroids in patients with lower mean baseline FEV, values. In one study patients receiving high doses of inhaled corticosteroids (1000-4000 $\mu \mathrm{g} /$ day beclomethasone or equivalent) with a mean baseline $\mathrm{FEV}_{1}$ of $63.5 \%$ predicted showed improved pulmonary function and asthma symptoms, as well as a lowered risk of asthma exacerbations, when a high dose of zafirlukast $(80 \mathrm{mg} /$ day $)$ was added to the treatment regimen. ${ }^{25}$

Previous montelukast studies using FEV as a primary end point have shown that montelukast provides additional asthma control for adults receiving inhaled beclomethasone $400 \mu \mathrm{g} / \mathrm{day}^{12}$ and children receiving inhaled budesonide $400 \mu \mathrm{g} /$ day by Turbuhaler. ${ }^{13}$ In these randomised controlled studies the mean baseline $\mathrm{FEV}_{1}$ values were $71.0 \%$ and $77.7 \%$ predicted, respectively, and asthma exacerbation days were significantly lower for montelukast treated patients (by 25\% and $23 \%$, respectively). Moreover, in both studies concomitant montelukast and inhaled corticosteroid treatment produced additive effects on peripheral blood eosinophil counts, with significantly lower counts than on corticosteroid alone, which suggests that corticosteroids and leukotriene receptor antagonists may have complementary anti-inflammatory activity. This complementary activity of montelukast may allow for the tapering of inhaled corticosteroid doses in stable patients while maintaining asthma control, as shown in a study by Löfdahl et al. ${ }^{26}$

In our study montelukast treated patients experienced symptomatic improvements, particularly in terms of decreased nocturnal waking because of asthma; 74\% (three of four patients) in this group slept all night during the study. The improvements in $\mathrm{FEV}_{1}$ during the study period were minimal and were similar in the two treatment groups; however, this is not an unexpected finding because mean baseline $\mathrm{FEV}_{1}$ was close to normal (mean $81 \%$ predicted) in these patients who were receiving treatment with inhaled corticosteroids. There were no differences in the asthma specific 
quality of life scores between the groups, which may be explained by the large variability in data as shown in the standard deviation values.

International consensus guidelines have proposed antileukotrienes as an alternative to long acting $\beta$ agonists for use as concomitant treatment with inhaled corticosteroids for patients with step 3 (moderate persistent) asthma. ${ }^{1}$ The NAEPP guidelines propose antileukotrienes as first line treatment for patients with step 2 (mild persistent) asthma. ${ }^{2}$ Antileukotrienes may have advantages over inhaled long acting $\beta$ agonists as additive treatment with corticosteroids, including an established anti-inflammatory activity ${ }^{11}$ that is different from, yet complementary to, that of inhaled corticosteroids (which do not reduce leukotriene production) and which long-acting $\beta$ agonists have not demonstrated in vivo. ${ }^{27-30}$ Other advantages may be the absence of tolerance to their bronchoprotective effects ${ }^{31-37}$ and the possibility that better patient compliance may be achieved with oral medications. ${ }^{38}$

There is little published information comparing antileukotrienes and long acting $\beta$ agonists when concomitantly administered with inhaled corticosteroids. Two studies have shown that salmeterol was superior to montelukast when added to inhaled corticosteroids in terms of PEFR (primary end point), symptom control, and supplemental salbutamol use. ${ }^{39}{ }^{40}$ Given the fact that salmeterol can be expected to have better bronchodilating properties than montelukast and because of the potential limitations of these studies, ${ }^{41}$ these results are neither surprising nor conclusive. There is a need for direct comparisons of antileukotrienes and long acting $\beta$ agonists as complementary therapy with inhaled corticosteroids that focus on other sensitive clinical end points to measure asthma inflammation control such as asthma exacerbations and asthma free days.

The strengths of this study include its large size, the wide age range of enrolled patients, and the range of doses of inhaled budesonide, all features that make the results more readily applicable to daily clinical practice. A possible limitation could be that the patient eligibility criteria, as in other clinical trials, may have selected a specific group of asthma patients. However, it should be noted that the results were consistent across all different doses of inhaled budesonide, even though patients entered the study receiving the dose of inhaled corticosteroid that was considered adequate for them for at least the previous 8 weeks. Moreover, the additive effects of montelukast were clinically and statistically significant despite evidence of a large placebo effect, especially with regard to global evaluations. This placebo effect, often evident in clinical trials of asthma treatment, ${ }^{42}{ }^{43}$ may result from the frequently repeated disease assessments and better adherence to treatment that occur in a clinical trial.

Montelukast was well tolerated with safety findings similar to those with placebo. The incidence of adverse events and of withdrawal because of an adverse event was similar in the two treatment groups.

In conclusion, for patients with mild airway obstruction and persistent asthma symptoms despite treatment with budesonide in doses of $400-1600 \mu \mathrm{g} /$ day by Turbuhaler, concomitant treatment with montelukast provides significant additional benefit and is well tolerated. Improved asthma control is evident in the increased percentage of asthma free days, the decreased percentage of asthma exacerbation days, and decreased $\beta$ agonist use.

\section{ACKNOWLEDGEMENTS}

The authors are indebted to Nieves Blanco for her excellent coordination of drug management and administrative aspects and to Dr Jonathan Leff for his continuous support and guidance. The study was supported by a grant from Merck Sharp \& Dohme Spain.

\section{APPENDIX}

The Casiopea Study Group (CApacidad de SIngulair Oral en la Prevención de Exacerbaciones Asmáticas (the ability of oral Singulair to prevent exacerbations of asthma)) for this clinical trial comprised the following investigators per study site:

H Dr Peset, Valencia (R Blanquer Oliva, I Inchaurraga Alvarez, J Palop Medina); H de Sagunto, Valencia (F Ripolles Peris, E Fernández Zabrellas, E Martínez Moragón, G Ruiz Jareño); H Xeral de Galicia, La Coruña (J R Rodríguez Suarez, M R Arias Castells, M Salgueiro Rodríguez, C Zamarron Sanz); H Provincial de Santiago, La Coruña (L G Valdés Cuadrado, D Alvarez García, P Penela Penela); H General de Elche, Alicante (C Shum Funk, J A Carratala Torregrosa, J C Padilla Estrada, V Romero Sanz); H Clínico y Provincial de Barcelona (C Picado Vallés, M T Luengo Planas); H General de Guadalajara (F Carrillo Arias, I Sánchez Hernández, J L Izquierdo Alonso); H Mutua de Terrassa, Barcelona (J L Heredia Budó); H Ntra Sra de Covadonga, Asturias (A Bango Alvarez, J Palicio Sopeña, J Martinez del Río); H Gran Canaria Dr Negrin, Las Palmas (P Cabrera Navarro, M V Medina Cruz, M F García Cabrera); H Virgen del Puerto, Cáceres (J A Riesco Miranda); H Carlos Haya, Málaga (A Valencia, J M García Jiménez, F Paez Codeso); H de la Princesa, Madrid (J Ancochea Bermúdez, M J Espinosa de los Monteros Garde); H Arnau de Vilanova, Valencia (B Brotons Brotons, J A Pérez Fernández, F Sánchez-Toril López); H Germans Trias i Pujol, Barcelona (J Morera Prat, C Martínez Rivera); H Arquitecto Marcide, La Coruña (M J Mejuto Marti, R de los Reyes Cruz, J M Moreno Barragan); H San Jorge, Huesca (L Borderías Clau, J Garrapiz López, P Val Adan); H de la Serranía, Málaga (J M Ignacio García); H San Juan, Alicante (E Chiner Vives, J Marco Such); H Valle de Hebron, Barcelona (P Lloberes Canadell, D N Aristizabal Roa, M L De Souza Galvao); H La Inmaculada, Almería (J Calvo Bonachera, J F Pascual Lledo); H Universitario La Fe, Valencia (M Perpiña Tordero, L Compte Torrero, A de Diego Damia); Fundación Jiménez Díaz, Madrid (J Sastre Domínguez, M Lluch Bernal, A Novalbos Wischer); H de Basurto, Vizcaya ( $\mathrm{J}$ A Crespo Notario, A Lahuerta Castro); H Virgen del Rocío, Sevilla (J Castillo Gómez, F Alvarez Gutierrez, G Soto Campos, J Sánchez Gómez); H Infanta Cristina, Badajoz (F Fuentes Otero, A M Castañar Jover, P Cordero Montero, P Iñigo Naranjo); H Francisco de Borja, Valencia (C Pellicer Ciscar, J Fullana Monllor, M J Cremades Romero); Consorci Sanitari de Mataro, Barcelona ( S Bardaji, X Vila Giralte); H de Cruces, Vizcaya (V Sobradillo Peña, V Achotegui Iraolagoitia, E Ciruelos Ayuso, P Marin, E Zenarruzabeitia Urigoitia); H Gregorio Marañon, Madrid (A Ventura Alvarez, T Vargas Hidalgo); H Santa Creu i Sant Pau, Barcelona (J Sanchis Aldás, P Casan Clara, V Plaza Mora, F Rodríguez Jerez); H Marques de Valdecilla, Santander (R Agüero Balbín); H Puerta del Mar, Cádiz (A León Jiménez, A Arnedillo Muñoz); H Universitario Lozano Blesa, Zaragoza (F Duce Gracia, C Colas Sanz, M A Domínguez Fuentes, J Fray Lazaro, A Lezaun Alfonso); Consorsi Sanitari de Terrassa, Barcelona (J Armengol Sánchez, A Llunell Casanova); H Clínico Virgen de la Victoria, Málaga (M Rosales Jaldo, N Avisbal Portillo, V Hidalgo San Juan); H de Requena, Valencia ( $\mathrm{J}$ J Soler Cataluña); H Cristal Piñor, Orense ( Lamela López, E Toubes Navarro, M Blanco Aparicio, J Tabara Rodríguez); H San Pedro Alcántara, Cáceres (J F Masa Jiménez, M J Martín Vicente, A Sojo González); H Universitario La Paz, Madrid (C Villasante Fernández-Montes, M S Serrano Peña, F J García Río); H Montecelo, Pontevedra (A Baloira Villar); Instituto Nacional de Silicosis, Asturias (J A Mosquera Pestaña, B Rodríguez Cocina); H San Eloy, Vizcaya (L Alberto Ruiz Iturriaga); H Juan Canalejo, La Coruña (H Verea Hernando, F Molina Nieto, I Otero González, A Veres Racamonde); H General de Albacete (J Martínez Moratalla); H Universitario de Canarias, Tenerife (I González Martín); H General Vic, Barcelona (J Serra Batlles); H 12 de Octubre, Madrid (P Martín Escribano, C Melero Moreno); H Joan March, Baleares (F Renom Sotorra, I Mir Viladrich, S Pons Vives); H General Yagüe, Burgos (J L Viejo Bañuelos, J García Muñoz, L Rodríguez Pascual); H de Mendaro, Guipuzcoa (M Azpiazu Blocona); H Militar de Burgos (I de Granda Orive, M T Peña Miguel, M C Reinares Ten, A Velayos Mayos); H Virgen de la Concha, Zamora (E Gutierrez Maire-Richard, J Muñiz Giron, T Antolín García, M Izquierdo Patron); Hospital Santa María Nai, Orense (M Tumbeiro Novoa, A Acuña Fernández, J M García Pazos); H Reina Sofía, Córdoba (A Cosano Povedano, J Cosano Povedano); H Ramón y Cajal, Madrid (A Sueiro Bendito, R Esteban Calvo, J Tamayo Sicilia); H General de Alicante (S Romero Candeira, A Candela Blanes); H Santa Marina, Vizcaya (E Ruiz de Gordejuela, L Zaldumbide Cacho); H Virgen de la Candelaria, Tenerife (J Batista Martín, I García Talavera); H Río Carrión, Palencia (M A Fernández Jorge, L Ramos Casado); H Virgen de la Luz, Cuenca (J M Peña Herrera, B Sánchez Sánchez); H Xeral-Cies, Vigo (L Piñeiro Amigo, J C Barros Tizón); H General Provincial de Pontevedra (E Temes Montes); H de Guipuzcoa (G Zubillaga Garmendia); H Axarquía, Málaga (A Domenech del Río, M Bentabol Manzanares); H General de Jerez, 
Cádiz (J F Carbonero de la Fuente); H Rio Hortega,Valladolid (J L Carretero Sastre, T Ruiz Albi); H Xeral-Calde de Lugo (L A Pérez del Llano); Clínica Puerta de Hierro, Madrid (J Estada Girauta, M J Ferreiro Alvarez, M T Lázaro Carrasco, A de Pablo Gafas); H de Manacor, Mallorca (R Irigaray Canals); H Ntra Sra de Valme, Sevilla (I Alfajeme Michavila, S Umbría Domínguez); H Severo Ochoa, Madrid (C Barbosa Ayucar, J de Miguel Díez); H de la Merced, Sevilla (R Vahí Maqueda, A Beiztegui Sillero); H Ciudad de Jaen (B Alcázar Lanagran); H Principe de Asturias, Madrid (F Canseco Gonzalez, E Alonso Peces); Hospital Santa Ana de Motril, Granada (F Cañizares Sevilla); H Univ Puerto Real, Cádiz (C García Vadillo); H de Mérida, Badajoz (G García de Vinuesa, J F Medina Gallardo ); H Torrecárdenas, Almería (A Maresca García-Esteller, G Villegas Sánchez); H Juan Ramón Jiménez, Huelva (J Maldonado Pérez); H Clínico San Carlos, Madrid (C Fernández).

\section{Authors' affiliations}

M J Vaquerizo, J Gonzalez-Esteban, Merck Sharp \& Dohme, Madrid, Spain

P Casan, J Sanchis, Department of Pneumology, H Santa Creu i Sant Pau, Barcelona, Spain

J Castillo, Pneumology and Thoracic Surgery Unit, H Virgen del Rocío, Sevilla, Spain

M Perpiña, Department of Pneumology, H Universitario La Fe, Valencia, Spain

V Sobradillo, Department of Pneumology, $\mathrm{H}$ de Cruces, Vizcaya, Spain

A Valencia, Department of Pneumology, H Carlos Haya, Málaga, Spain H Verea, Department of Pneumology, H Juan Canalejo, La Coruña,

Spain

J L Viejo, Department of Pneumology, H General Yagüe, Burgos, Spain C Villasante, Department of Pneumology, H Universitario La Paz, Madrid, Spain

C Picado, Department of Pneumology, H Clínico y Provincial, Barcelona, Spain

\section{REFERENCES}

1 National Institutes of Health, National Heart, Lung and Blood Institute. Global initiative for asthma. Pocket guide for asthma management and prevention. NIH publication no. 96-3659B. Bethesda, MD: National Institutes of Health, 1998

2 National Asthma Education and Prevention Program. Expert Panel Report II: Guidelines for the diagnosis and management of asthma. NIH publication no. 97-4051. Bethesda, MD: National Institutes of Health, 1997.

3 Barnes PJ. Inhaled glucocorticoids for asthma. N Engl J Med 1995;332:868-75.

4 Keatings VM, Jatakanon A, Worsdell YM, et al. Effects of inhaled and oral glucocorticoids on inflammatory indices in asthma and COPD. Am Respir Crit Care Med 1997;155:542-8.

5 Kharitonov SA, Yates DH, Barnes PJ. Inhaled glucocorticoids decrease nitric oxide in exhaled air of asthmatic patients. Am J Respir Crit Care Med 1996;153:454-7

6 O'Shaughnessy KM, Wellings R, Gillies B, et al. Differential effects of fluticasone propionate on allergen-evoked bronchoconstriction and increased urinary leukotriene E4 excretion. Am Rev Respir Dis $1993 ; 147: 1472-6$

7 Dworski R, Fitzgerald GA, Oates JA, et al. Effect of oral prednisone on airway inflammatory mediators in atopic asthma. Am J Respir Crit Care Med 1994;149:953-9.

8 Hay DWP, Torphy TJ, Undem BJ. Cysteinyl leukotrienes in asthma: old mediators up to new tricks. Trends Pharmacol Sci 1995;16:304-9.

9 Laitinen LA, Laitinen A, Haahtela T, et al. Leukotriene E4 and granulocyte infiltration into asthmatic airways. Lancet 1993;341:98990.

10 Drazen JM, Israel E, O'Byrne PM. Treatment of asthma with drugs modifying the leukotriene pathway. N Engl J Med 1999;340:197-206.

11 Pizzichini E, Leff JA, Reiss TF, et al. Montelukast reduces airway inflammation in asthma: a randomized, controlled trial. Eur Respir J 1999;14:12-18.

12 Laviolette M, Malmstrom K, Lu S, et al. Montelukast added to inhaled beclomethasone in treatment of asthma. Am J Respir Crit Care Med 1999; 160: 1862-8

13 Simons FER, Villa JR, Lee BW, et al. Montelukast added to budesonide in children with persistent asthma: a randomized, double-blind, crossover study. J Pediatr 2001;138:694-8.

14 Santanello NC, Barber BL, Reiss TF, et al. Measurement characteristics of two asthma symptom diary scales for use in clinical trials. Eur Respir $J$ 1997; 10:646-51.

15 American Thoracic Society. Standardization of spirometry, 1994 update. Am J Respir Crit Care Med 1995;152:1107-36.
16 Sanchis J, Casan P, Castillo J, et al. SEPAR. Normativa para la práctica de la espirometría forzada. Arch Bronconeumol 1989;25:132-42.

17 Juniper EF, Guyatt GH, Epstein RS, et al. Evaluation of impairment of health-related quality of life in asthma: development of a questionnaire for use in clinical trials. Thorax 1992:47:76-83.

18 Wilding $\mathbf{P}$, Clark $M$, Thompson Coon J, et al. Effect of long term treatment with salmeterol on asthma control: a double blind, randomised crossover study. BM 1997;314:1441-6.

19 Chan-Yeung $M$, Chang JH, Manfreda J, et al. Changes in peak flow, symptom score, and the use of medications during acute exacerbations of asthma. Am J Respir Crit Care Med 1996;154:889-93.

20 Pauwels RA, Löfdahl CG, Postma DS, et al. Effect of inhaled formoterol and budesonide on exacerbations of asthma. Formoterol and Corticosteroids Establishing Therapy (FACET) International Study Group. N Engl J Med 1997;337:1405-11.

21 Gardner MJ, Altman DG. Estimating with confidence. BM (Clin Res Ed) 1988:296:1210-1.

22 Randles RH, Wolfe DA. Introduction to the theory of nonparametric statistics. Florida: Krieger Publishing Company, 1991

23 Breslow NE, Day NE. The analysis of case control studies. In: Statistical methods in cancer research. Vol I. Lyon: International Agency for Research on Cancer (IARC), 1980.

24 Sculpher MJ, Buxton M. The episode-free day as a composite measure of effectiveness: an illustrative economic evaluation of formoterol versus salbutamol in asthma therapy. Pharmacoeconomics 1993;4:345-52.

25 Virchow JC Jr, Prasse A, Naya I, et al. Zafirlukast improves asthma control in patients receiving high-dose inhaled corticosteroids. Am J Respir Crit Care Med 2000;162:578-85.

26 Löfdahl C-G, Reiss TF, Leff JA, et al. Randomized, placebo controlled trial of effect of a leukotriene receptor antagonist, montelukast, on tapering inhaled corticosteroids in asthmatic patients. BM 1999:319:87-90

27 Roberts JA, Bradding P, Britten KM, et al. The long-acting beta2-agonist salmeterol xinafoate: effects on airway inflammation in asthma. Eur Respir J 1999;14:275-82.

28 Gardiner PV, Ward C, Booth H. Effect of 8 weeks of treatment with salmeterol on bronchoalveolar lavage inflammatory indices in asthmatics. Am J Respir Crit Care Med 1994;150:1006-1 1.

29 Kraft $M$, Wenzel SE, Bettinger CM, et al. The effect of salmeterol on nocturnal symptoms, airway function, and inflammation in asthma. Chest 1997;111:1249-54.

30 Dempsey OJ, Wilson AM, Sims EJ, et al. Additive anti-inflammatory effects of montelukast but not salmeterol in asthmatics suboptimally controlled on inhaled steroids (abstract). Am J Respir Crit Care Med 2000;161:A198

31 Leff JA, Busse WW, Pearlman D, et al. Montelukast, a leukotriene-receptor antagonist, for the treatment of mild asthma and exercise-induced bronchoconstriction. N Engl J Med 1998;339: 147-52.

32 Reiss TF, Chervinsky P, Dockhorn R, et al. Montelukast, a once daily leukotriene receptor antagonist, in the treatment of chronic asthma. A multicenter, randomized, double-blind trial. Arch Intern Med 1998; 158:1213-20.

33 Villaran C, O’Neill SJ, Helbling A, et al. Montelukast versus salmeterol in patients with asthma and exercise-induced bronchoconstriction. J Allergy Clin Immunol 1999; 104:547-53.

34 Edelman JM, Turpin JA, Bronsky EA, et al. Oral montelukast compared with inhaled salmeterol to prevent exercise-induced bronchoconstriction: a randomized double-blind trial. Ann Intern Med 2000;132:97-104.

35 Cheung D, Timmers MC, Zwinderman $\mathrm{AH}$, et al. Long-term effects of a long-acting beta 2-adrenoceptor agonist, salmeterol, on airway hyperresponsiveness in patients with mild asthma. N Engl J Med 1992:327: $1198-203$

36 Yates DH, Kharitonov SA, Barnes PJ. An inhaled glucocorticoid does not prevent tolerance to the bronchoprotective effect of a long-acting inhaled B2-agonist. Am J Respir Crit Care Med 1996;154:1603-7.

37 Simons FER, Gerstner TV, Cheang MS. Tolerance to the bronchoprotective effect of salmeterol in adolescents with exercise induced asthma using concurrent inhaled glucocorticosteroid treatment. Pediatrics 1997;99:655-9.

38 Kelloway JS, Wyatt RA, Adlis SA. Comparison of patients' compliance with prescribed oral and inhaled asthma medications. Arch Intern Med 1994:154:1349-52.

39 Nelson HS, Busse WW, Kerwin E, et al. Fluticasone propionate/ salmeterol combination provides more effective asthma control than low-dose inhaled corticosteroid plus montelukast. J Allergy Clin Immunol 2000; 106:1088-95

40 Fish JE, Israel E, Murray JJ, et al. Salmeterol powder provides significantly better benefit than montelukast in asthmatic patients receiving concomitant inhaled corticosteroid therapy. Chest $2001 ; 120: 423-30$

41 Virchow JC. Salmeterol powder provides significantly better benefit than montelukast in asthmatic patients receiving concomitant inhaled corticosteroid therapy (letter). Chest 2002;121:2083-4.

42 Godfrey S, Silverman M. Demonstration by placebo response in asthma by means of exercise testing. J Psychosom Res 1973;17:293-7.

43 Joyce DP, Jackevicius C, Chapman KR, et al. The placebo effect in asthma drug therapy trials: a meta-analysis. J Asthma 2000;37:303-18. 
PostScript

\section{LETTERS TO THE EDITOR}

If you have a burning desire to respond to a paper published in Thorax, why not make use of our "rapid response" option? Log on to our website (www.thoraxjnl.com), find the paper that interests you, and send your response via email by clicking on the "eletters" option in the box at the top right hand corner.

Providing it isn't libellous or obscene, it will be posted within seven days. You can retrieve it by clicking on "read eletters" on our homepage.

The editors will decide as before whether to also publish it in a future paper issue.

\section{Unusual lung consolidation in SLE}

Pulmonary manifestations of systemic lupus erythematosus (SLE) include acute lupus pneumonitis, chronic interstitial pneumonitis, diaphragmatic dysfunction, atelectasis, pulmonary vascular disease, upper airway dysfunction, and bronchiolitis obliterans. Pneumonia due to infection also develops because infection is a major cause of death of patients with SLE. ${ }^{23}$ Here, we report a patient with SLE who suffered from an ambulatory lung consolidation devoid of pathogens.

A 61 year old woman with SLE had been treated with $10 \mathrm{mg}$ prednisolone every other day since 1990 without deterioration in the disease. She had complained of cough, nonpurulent sputum, and fever once or twice month since September 1998 which resolved spontaneously within a few days. In October 1999 she was first admitted to hospital with a lung consolidation and an ambient faint infiltrate over the left S4 and S6b on the chest radiograph and computed tomographic (CT) scan (fig 1A, D). She had pancytopenia, increased levels of $\mathrm{C}$ reactive protein and $\mathrm{LDH}$ a high titre of anti-double strand DNA antibody, and decreased levels of complement titres. Analysis of bronchoalveolar lavage fluid and histopathological examination of transbronchial lung biopsy specimens showed an increased number of lymphocytes with a low $\mathrm{CD} 4 / \mathrm{CD} 8$ ratio. The presence of neither microorganisms nor granulomas was confirmed. She was discharged because the consolidation was reduced (fig 1B, E). In March 2000 she had another bronchoscopic examination because of deterioration of the consolidation (fig IC, F) but the results were the same as in 1999. For the purpose of further examination we conducted a partial lung resection. The affected lung tissue histopathologically showed a non-specific inflammatory nodule which consisted of lymphocyte dominan inflammatory cell infiltration, lymph follicle formation, fibrosis, fibrin exudation, a thickened alveolar septum, and collapsed alveoli without infectious microorganisms or malignant cells. Removal of the affected lung tissue resulted in improvement in symptoms and abnormal data.

Non-specific inflammatory nodules might occur as a complication of SLE, and a surgical intervention should be considered to diagnose and treat the disease.

A Nomura, Y Morishita, T lijima, Y Ishii, H Satoh, T Sakamoto, Y Uchida,

T Homma, M Ohtsuka, K Sekizawa

Department of Pulmonary Medicine, Institute of Clinical Medicine, University of Tsukuba, Tsukuba, lbaraki, Japan

Correspondence to: Dr K Sekizawa, Department of Pulmonary Medicine, Institute of Clinical Medicine, University of Tsukuba, 1-1-1 Tennoudai, Tsukuba, baraki 305-8575, kiyo-se@md.tsukuba.ac.jp

\section{References}

1 King TE Jr, Cherniack RM, Schwarz MI. The lungs and connective tissue diseases. In: Murray JF, Nadel JA, eds. Textbook of

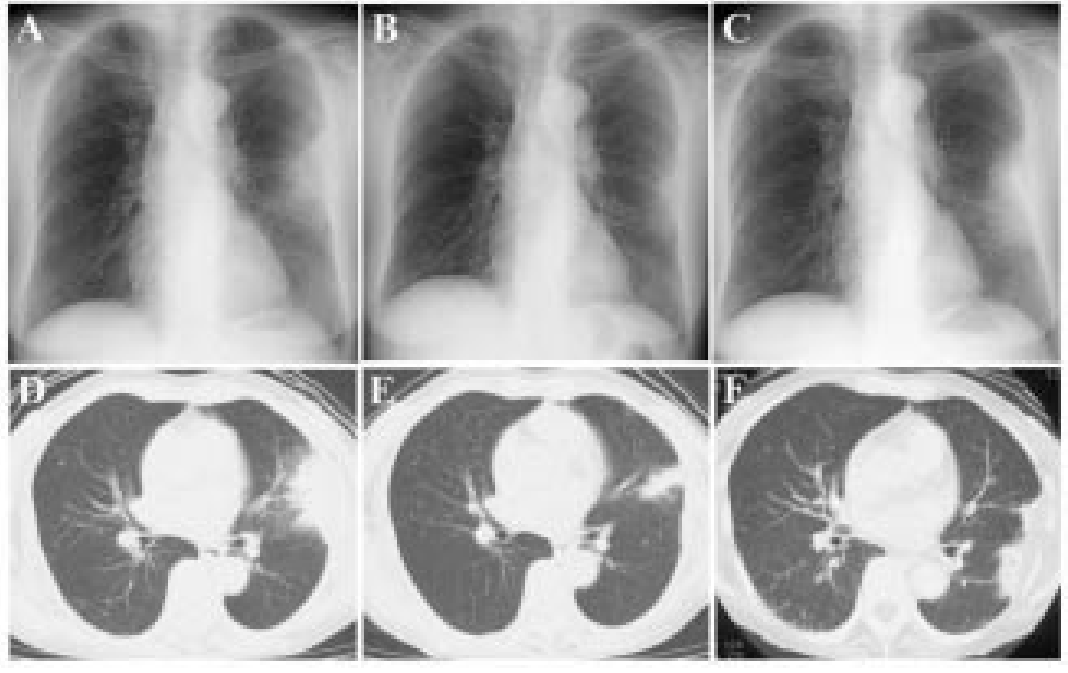

Figure 1 Chest radiograph and CT scan on first admission (A, D), at partial improvement (B, $E$ ), and on second admission (C, F) showing deterioration and improvement of a fan shaped patchy shadow on the pleura. respiratory medicine. Philadelphia: WB Saunders, 1994: 1850-72

2 Jarrett MP, Santhanam S, Del Greco F. The clinical course of end-stage renal disease in systemic lupus erythematosus. Arch Intern Med 1983;143:1353-6.

3 Cervera R, Khamashta MA, Font J, et al. Morbidity and mortality in systemic lupus erythematosus during a 5-year period. A erythematosus during a 5-year period.
multicenter prospective study of 1000 patients. European Working Party on Systemic Lupus Erythematosus. Medicine (Baltimore) 1999;78:167-75.

\section{Atypical mycobacterial infection, starvation and effect of BCG vaccination on tuberculin skin test}

Wang et al ${ }^{1}$ are right when they underline the need to adjust for confounding variables when analysing the results of a tuberculin skin test (TST) survey, but they are oversimplistic when, using surveys done in many countries worldwide, they study only the effect of the BCG vaccination on the TST results. The authors did not discuss the rate of atypical mycobacterial infection in a population, an important confounding factor that drives up the rate of tuberculous infection, because atypical mycobacteria crossreact with Mycobacterium tuberculosis. Unlike Wang et al, at least one TST survey included in the metaanalysis, done in Kenya, ${ }^{2}$ adjusted for the rate of atypical mycobacterial infection. A study performed in the Netherlands on army recruits which double tested for both $M$ tuberculosis and atypical mycobacteria showed that $48 \%$ of the reactors with indurations in the range $10-15 \mathrm{~mm}$ and $16 \%$ with indurations $\geqslant 10 \mathrm{~mm}$ were classified as false positive. ${ }^{3}$ There was no interaction between BCG and TST as long as the recruits were not BCG vaccinated. False positives were then excluded from the latent tuberculosis infection treatment.

Another confounding factor in this metaanalysis is pooling together TST results from surveys performed in populations during the post-war period of starvation ${ }^{4}$ with those from developed countries without considering the effect of a low calorie diet on the TST results. Only 3-4 months after BCG vaccination the rate of apparent TST conversion in malnourished children may be as low as $23 \%$ compared with $85 \%$ in well nourished children. $^{5}$

The rate of atypical mycobacterial infection might therefore have been confused for the TST positivity due to BCG vaccination, while the effect of BCG vaccination on the rate of TST positivity was underestimated in starving populations

The author did not need financial support to write this letter and does not have any material interest in the subject.

M-S Jalba

Public Health Epidemiologist, New York City Department of Health and Mental Hygiene Tuberculosis Control Program

Correspondence to: Dr M S Jalba 17-15 Woodbine Street, Apartment 3L, Ridgewood, New York 11385, USA msj@about.com 


\section{References \\ 1 Wang L, Turner MO, Elwood RK, et al. A meta-analysis of the effect of Bacille Calmette Guerin vaccination on tuberculin skin test measurements. Thorax 2002;57:804-9. \\ 2 Bosman MC, Swai OB, Kwamanga DO, et al. National tuberculin survey of Kenya, 1986-1990. Int J Tuberc Lung Dis 1998:2:272-80. \\ 3 Bruins J, Gribnau JH, Bwire R. Investigation into typical and atypical tuberculin sensitivity in the Royal Netherlands Army, resulting in a more rational indication for isoniazid prophylaxis. Tuberc Lung Dis 1995;76:540-4. \\ 4 Azbite M. Tuberculin survey in Ethiopia Kekkaku 1992;67:539-44. \\ 5 Chandra RK. Nutrition, immunity and infection: present knowledge and future directions. Lancet 1983; 1:688-91.}

\section{Authors' reply}

We would like to thank Dr Jalba for the thoughtful comments on our paper. As the prevalence of atypical mycobacterial infection was not systematically evaluated in the studies we reviewed, we could not integrate this into our analysis. From a practical point of view both BCG and non-BCG groups are likely to have similar exposures to atypical infection, and clinicians would not be able to assess routinely for such infections. Similarly, information on nutrition was not systematically available but, as a surrogate, we have looked a the impact of BCG as one moves further from the equator and found no differences in its impact. On the basis that malnutrition would be a greater confounder in studies done close to the equator, this suggests that nutrition is not a significant factor in the sample size we have generated.

J M FitzGerald, M O Turner, L Wang, M Schulzer, R K Elwood

Respiratory Division, Vancouver Hospital, 2775 Heather Street, Vancouver, BC, Canada V5Z 3JT; markf@interchange.ubc.ca

\section{Improving surgical resection rates in lung cancer without a two stop service}

In 1998 the Papworth Thoracic Oncology Unit published their data from the first year of a two stop clinic. By this means they improved their surgical resection rates for patients with non-small cell lung cancer (NSCLC) from $10 \%$ to $25 \%$. $^{1}$ This paper is quoted as the benchmark for surgical resection in the UK. In 1998 the surgical resection rate for patients with NSCLC in Hammersmith Hos pitals Trust was $4.7 \%$ (three of 64 patients). In March 2000 we set up rapid access clinics to assess both patients with abnormal chest radiographs and urgent GP referrals. In accordance with the National Service Framework (NSF), ${ }^{2}$ multidisciplinary team meetings (MDTM) between respiratory medicine, radiology, cardiothoracic surgery, oncology and palliative medicine were established.

From April 2000 inpatients and outpatients with a chest radiograph suspicious for lung cancer were referred directly from radiology to one of two rapid access clinics within the Trust. Local GPs, outpatient departments, and the emergency department also referred patients. There were no tertiary referrals. All patients were given appointments within the
2 week time period required by the NSF. Patients were told they were being investigated for an abnormal radiograph and would need further investigation with a CT scan and may require a bronchoscopy (FOB) and/or fine needle aspiration/biopsy (FNAB). Written information was given at that point regarding CT scanning, FOB, and FNAB. Staging and tissue diagnosis was completed within 2 weeks.

All results were reviewed in the MDTM and management plans were made and recorded Following the MDTM, patients were reviewed in a joint clinic with the Macmillan nurse and introduced to either the oncologist or the thoracic surgeon. All data on every aspect of the patient's management were collected prospectively.

From l April 2000 to 31 March 2001194 patients were seen ( 118 men). In 100 patients cancer was the most likely diagnosis (56 men and 44 women, mean age 67 years, range 26-95). Six patients declined further investigation. $94(95 \%)$ patients had a finite histological diagnosis: 84 primary lung cancers, three secondary lung cancers, two carcinoid tumours, two Hodgkin's disease, and three mesothelioma.

Of the 84 patients with lung cancer, 14 had small cell carcinoma and 70 had NSCLC. Of the 70 patients with NSCLC, 20 (28.5\%) were referred for thoracotomy ( 11 men, mean age 64 years, range 48-81). Nineteen patients ( $27 \%$ of NSCLC; $23 \%$ of the whole cohort) had a successful resection, 17 lobectomies (stages 5Ia, 3Ib, 3IIa, 3IIb and 3IIIa) and two pneumonectomies (stages IIIb and Ia). One patient $(5 \%)$ had a failed thoracotomy due to a cardiac event. In five cases (all Ia) the ches radiograph had been taken routinely before another operative procedure and three (Ia and IIIa) were routine outpatient radiographs in asymptomatic patients. There were no postoperative deaths. Two patients (pIIIa) subsequently died at 9 and 11 months, respectively. Currently, the l year survival rate for the whole cohort of patients with proven lung cancer is $46 \%$.

With no additional resources we have successfully implemented the lung cancer NSF and have significantly improved our surgical resection rates from $4.7 \%$ in 1998 to $27 \%$ of patients with NSCLC and $23 \%$ of our whole lung cancer cohort. This is equivalent to the benchmark series for surgical resection in the UK but, unlike that series, none of the patients were tertiary referrals. ${ }^{1}$ Our large increase in resection rate was not due to a more aggressive surgical approach as $80 \%$ of the cases were stage IIb or better, and our failed thoracotomy rate of $5 \%$ is similar to

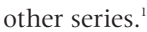

We have shown that, without the resources to establish a two stop service we have still established a rapid and effective patient pathway culminating in an MDTM and joint clinic This has produced resection rates considerably better than those previously achieved and a 1 year survival rate that compares very favourably with published UK survival figures.

E F Bowen, J R Anderson, M E Roddie Hammersmith \& Charing Cross Hospitals NHS Trust, Du Cane Road, London W12 OHN, UK fbowen@hhnt.org

\section{References}

1 Laroche C, Wells F Coulden R et al. improving surgical resection rates in lung cancer. Thorax 1998;53:445-9.
2 Department of Health. Improving the quality of cancer services. London: Department of Health, 2000.

3 Janssen-Heijnen ML, Gatta G, Forman D, et al. Variation in survival of patients with lung cancer in Europe, 1985-1989. Eur J Cancer 1998;34:2191-6.

\section{Publication of complex dataset}

In the April 2002 issue of Thorax we published a paper on airway inflammation, basement membrane thickening and bronchial hyperresponsiveness in asthma. ${ }^{1}$ In this study we examined the effects over 12 months of inhaled corticosteroid therapy on reticular basement membrane thickening in asthmatic airways and how this may influence airway hyperresponsiveness.

Shortly before, at the end of 2001, we also published a paper in the American Journal of Respiratory and Critical Care Medicine ${ }^{2}$ which dealt with the baseline data on reticular basement membrane thickness for the same group of patients. The analysis dealt with the relationship between reticular basement membrane thickness, fixed airflow limitation, and a novel test of airway distensibility.

The existence of the respective papers was made clear to and discussed with the respective editors during each editorial process. The review process was long and exhaustive, continuing over many months. Mainly because of the temporal overlap of the two review processes, the paper in the American journal is not referenced in the Thorax paper.

Because of the increased sensitivity about potential for duplicate publication, ${ }^{34}$ we wish to make clear to the Thorax readership the existence of the two papers from the same study, although the overlap between them is small and explicit, and the analyses contained within each quite distinct. With hindsight, the joint source of these data should have been acknowledged in the published paper.

\section{E H Walters}

Department of Clinical Sciences, University of Tasmania Medical School, Hobart, Tasmania 7001,Australia; haydn.walters@utas.edu.au

\section{References}

1 Ward C, Pais M, Bish R, et al. Airway inflammation, basement membrane thickening and bronchial hyperresponsiveness in asthma Thorax 2002:57:309-16.

2 Ward C, Johns DP, Bish R, et al. Reduced airway distensibility, fixed airflow limitation, and airway wall remodeling in asthma. $\mathrm{Am} J$ Respir Crit Care Med 2001;164:1718-21.

3 Tobin MJ. AJRCCM's policy on duplicate publication. Am J Respir Crit Care Med 2002;166:433-7.

4 Editorial. Notice of duplicate publication. Thorax 2002;57:6.

\section{Successful treatment of BALT lymphoma with combined chemotherapy}

Primary pulmonary lymphoma arising from mucosa- or bronchus-associated lymphoid tissue (MALT or BALT) is a rare disease. ${ }^{12}$ We report a 30 year old man with low grade B cell BALT lymphoma who presented with a bulky mass in the lung and was treated successfully with cyclophosphamide, doxorubicin, vincristine and prednisone (CHOP) combined chemotherapy. 

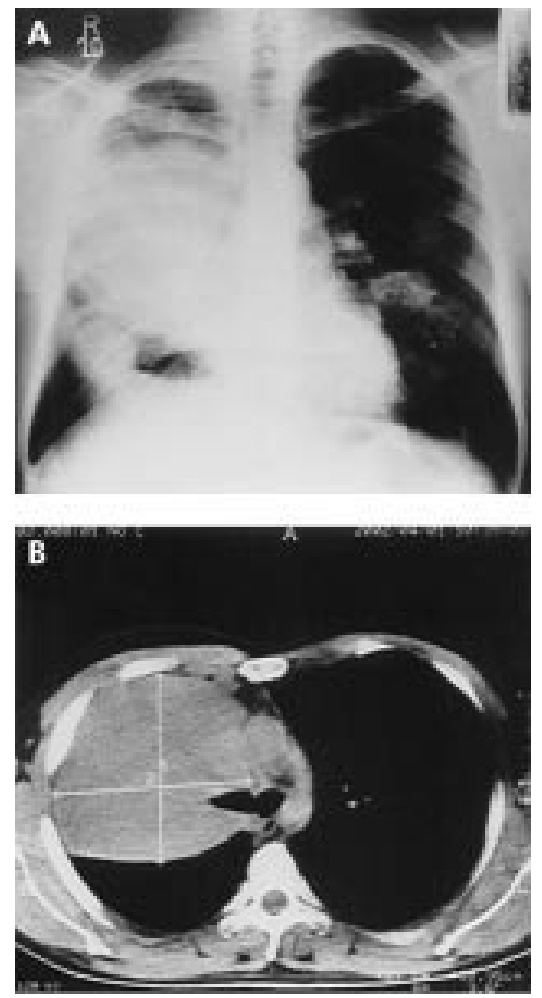

Figure 1 (A) Posteroanterior chest radiograph showing a bulky mass in the right lung, a smaller mass in the lower zone of the right lung, and heterogeneous infiltration in the middle zone of the left lung. (B) CT scan of the chest showing a bulky mass in the right lung.

The patient was admitted with a dry cough, shortness of breath, back pain, and progressive infiltrates on chest radiographs. He had no history of risks for BALT lymphoma. ${ }^{134} \mathrm{No}$ rash or lymphadenopathy or organomegaly was detected. A CT scan of the chest showed a right mid lung bulky mass with a diameter of $10.9 \times 10.6 \mathrm{~cm}$ and infiltrations in both lung fields (fig 1). A transbronchial biopsy specimen was compatible with low grade (B cell lymphoplasmocytoid type) lymphoma. Immunohistochemical examination showed a monoclonal membrane surface $\kappa$ light chain positive. The patient underwent combined chemotherapy (CHOP) which was repeated every 3 weeks. He tolerated the treatment without difficulty, his symptoms improved, and CT scans after completion of six courses of treatment showed a marked reduction in the lesions in both lung fields (fig 2).

BALT lymphoma shows an indolent course and remains localised for a prolonged period of time, with systemic dissemination occurring late in the clinical course. ${ }^{2}$ Recommended treatment options include complete surgical resection, radiotherapy, or chemotherapy. The role of surgery in the management of primary lymphoma of the lung is twofold: (1) to obtain diagnostic tissue and (2) to obtain a therapeutic resection. In our case we used combined chemotherapy because surgical intervention is of limited use in patients with a large non-resectable lesion or bilateral lung disease. ${ }^{2}$

We conclude that, in patients with a large or bilateral pulmonary BALT lymphoma, transbronchial or transthoracic biopsy and mediastinoscopy are useful diagnostic procedures
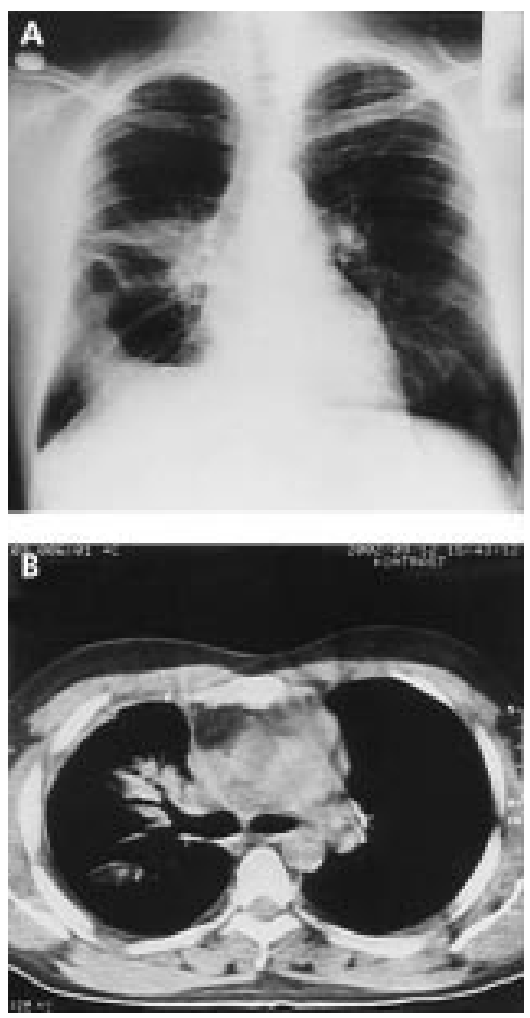

Figure 2 (A) Posteroanterior chest radiograph and (B) CT scan showing marked reduction in the lesions shown in fig 1.

for obtaining a definitive diagnosis ${ }^{5}$ and treatment with combined chemotherapy should be considered.

R Ali, F Özkalemkaş, T Özçelik, V Özkocaman, Ü Ozan, A Tunalı

Division of Hematology, Department of Internal Medicine, Uludağ University School of Medicine, Bursa, Turkey

G Filiz

Department of Pathology, Uludağ University Schoo of Medicine

O Gözü

Department of Chest and Tuberculosis, Uludag University School of Medicine

Correspondence to: Associate Professor R Ali, Uludağ Üniversitesi Tıp Fakültesi Hematoloji Bilim Dalı, 16059 Görükle, Bursa, Turkey ridvanali@uludag.edu.tr

\section{References}

1 Kurosu K, Yumoto N, Furukawa M, et al. Low-grade pulmonary mucosa-associated lymphoid tissue lymphoma with or without intraclonal variation. Am J Respir Crit Care Med 1998;158:1613-9

2 Ferraro P, Trastek VF, Adlakha $\mathrm{H}$, et al. Primary non-Hodgkin's lymphoma of the lung. Ann Thorac Surg 2000;69:993-7.

3 Orchard TR, Eraut CD, Davison AG. Non-Hodgkin's lymphoma arising in cryptogenic fibrosing alveolitis. Thorax 1998;53:228-9.

4 Toyoshima M, Chida K, Sato A. Antigen uptake and subsequent cell kinetics in bronchus-associated lymphoid tissue. Respirology 2000;5: 141-5.

5 King LJ, Padley AC, Wotherspoon AC, et al. Pulmonary MALT lymphoma: imaging findings in 24 cases. Eur Radiol 2000;10:1932-8.

\section{Obstructive sleep apnoea can directly cause death}

A 52 year old woman was referred for investigation of daytime somnolence. She complained of heavy snoring, unrefreshing disturbed sleep, and had fallen asleep while driving. She had an Epworth score ${ }^{1}$ of 24/24, a history of hypertension controlled on losartan, had never smoked, and only took occasional alcohol. She had limited mobility as a result of her extreme obesity $(168 \mathrm{~kg}$ ) with a height of $1.58 \mathrm{~m}\left(\mathrm{BMI} 67.3 \mathrm{~kg} / \mathrm{m}^{2}\right)$. Her chest was clinically clear $\left(\mathrm{FEV}_{1} 1.8 \mathrm{l}\right.$, FVC 2.31 ) and her serum bicarbonate level was $31 \mathrm{mmol} / \mathrm{l}$, implying a degree of hypercapnia. She had a trace of oedema but no evidence of cardiac failure.

She was admitted 1 month later for a sleep study. Data collection included oximetry, pulse rate, movement and sound (SSI Visilab). At 04.30 hours the nursing staff found her lying dead across the bed. The oxygen saturation by pulse oximetry was $91 \%$ at the start of the night in a sitting position. Good data were obtained for the first 25 minutes of the study, the remainder being highly fragmented with values fluctuating between $90 \%$ and the instrument cut off level of $25 \%$. The video showed a repeated but irregular pattern of apnoea, snoring, arousal, sitting up, falling asleep, and lying back into the supine position. From one such apnoea she failed to rouse sufficiently to resume breathing and suffered a cardiorespiratory arrest. Post mortem examination showed some coronary atheroma but, crucially, no occlusion, leading to the conclusion that the death was directly attributable to obstructive sleep apnoea (OSA). Lungs, liver and spleen showed some congestion consistent with the post mortem diagnosis of acute cardiorespiratory failure.

The coroner initially expressed concern that the patient was not being directly observed. After discussion it was accepted that a sleep test is not monitoring in the usual sense but is an exercise in data collection performed either in hospital or at home for reasons of organisational convenience.

This recorded death directly resulting from OSA in combination with severe obesity is unlikely to be unique and may be unusual only in that it was captured on the video recording. In such extreme cases recognising the component of OSA may be difficult as the oximetry recording is erratic rather than the familiar "saw tooth" waveform. A number of mechanisms associating OSA with increased morbidity and mortality have been proposed, significantly obesity and ventilatory failure ${ }^{2}$ and vascular disease. ${ }^{3}$ However, this case demonstrates a causal connection.

Attributing unexpected deaths to cardiac events rather than to OSA may conceal a number of deaths directly caused by OSA.

\section{S Pearce}

University Hospital of North Durham, Durham DH1 5TW, UK; sarah.pearce@ndhent.northy.nhs.uk

\section{P Saunders}

Regional Medical Physics Department, University Hospital of North Durham, Durham DHI 5TW, UK

\section{References}

1 Johns MW. A new method for measuring daytime sleepiness: The Epworth sleepiness scale. Sleep 1991;14:540-1.

2 Stradling JR. Handbook of sleep-related breathing disorders. Oxford: Oxford University Press, 1993: 56-7.

3 Lanfranchi P, Somers VK. Obstructive sleep apnoea and vascular disease. Respir Res $2001 ; 2: 315-9$ 


\section{Pancoast's syndrome as a result of metastatic renal cell carcinoma}

Infections, lymphomas, and metastase ${ }^{1-3}$ are unique causes of Pancoast's syndrome. The most common aetiological factor is non-small cell lung cancer (NSCLC). Pancoast's syndrome resulting from metastatic renal cell carcinoma (RCC) has not previously been reported. We present the case of a metastatic Pancoast tumour in the left lung in a patient who had previously undergone resection for RCC.

A 49 year old woman was admitted with a pain in the left shoulder radiating to the arm which had been present for several months, eight years after excision of the left kidney for clear cell RCC. Computed tomographic scans of the chest and abdomen revealed a solitary irregular mass $(4.5 \mathrm{~cm})$ in the apical segment of the left lung adhering to the thoracic inle with no evidence of local recurrence in the abdomen.

Extrapleural resection of the tumour with the apical segment of the lung was performed. Histological examination proved the metastatic origin of the tumour from RCC. Nine months after resection of the metastatic tumour the patient had a relapse in the left thoracic inlet. Residual left upper lobectomy with excision of ribs 1-4 and the infiltrated part of the brachial plexus was performed. Seven months later the patient underwent radiation therapy to the tumour bed and supraclavicular region because of metastases in the scalene nodes (total dose $60 \mathrm{~Gy}$ in 27 fractions over 41 days).

Twenty five months after the first metastatic resection the patient's general condition deteriorated due to dissemination of the disease. Radiological examination showed several new foci in both lungs and a metastatic tumour in the brain. The patient died 31 months after the first thoracotomy and 11 years after nephrectomy.

We conclude that metastatic RCC should be considered as a possible cause of Pancoast's syndrome. The resection should be as radical as in NSCLC - if necessary involving the adjacent structures-which should have been done in our first operation.

T W Marjanski, W Rzyman, J Skokowski

Thoracic Surgery Department, Medical University of Gdansk, Poland; wrzyman@amg.gda.pl

\section{References}

1 Chang CF, Su WJ, Chou TY, et al.

Hepatocellular carcinoma with Pancoast's syndrome as an initial symptom: a case report. Jpn J Clin Oncol 2001;31:119-21.

2 Goldman SM, Fajardo AA, Naraval RC, et al. Metastatic transitional cell carcinoma from the bladder: radiographic manifestations. AJR 1979;132:419-25.

3 Amin R. Bilateral Pancoast's syndrome in a patient with carcinoma of the cervix. Gynecol Oncol 1986;24:126-8.

\section{BOOK REVIEW}

\section{The Clinician's Guide to Asthmo}

Kian Fan Chung. London: Arnold. 165 pp. $£ 29.99$. ISBN $034076287 \mathrm{X}$

This is an easy to read and thorough guide to asthma which covers a wide range of topics from prevalence to treatment, pharmacology to pathology. The text is engaging and interesting. It is well illustrated with numerous pictures and diagrams that enhance its readability. The strength of this book lies in its clarity. Even the chapter on the pathophysiology of asthma can be read and understood by those who feel weak at the very mention of cytokines! It is also a contemporary text and provides a useful insight into emerging ideas and novel treatments in this field. The book is suited to those who wish to obtain a broad overview of the subject and would suit medical and MRCP students, respiratory trainees, and other health professionals involved in the care of the asthmatic patient.

Although the management of the asthmatic patient is covered in detail, this is not a handbook to guide individual patient care but is, instead, a concise and thoughtful review of the disease.

In summary, if asthma is not your primary field of interest and you were asked to give a talk on the subject tomorrow, you would be well advised to hunt out this book.

C M Richardson Department of Respiratory Medicine, Glenfield Hospital, Groby Road, Leicester LE3 9QP, UK. catherine.richardson@tyne007.freeserve.co.uk

\section{CORRECTION}

Montelukast and inhaled budesonide in mild to moderate asthma

In the paper entitled "Effect of montelukast added to inhaled budesonide on control of mild to moderate asthma" by M J Vaquerizo $e$ al which appeared in the March issue of Tho$\operatorname{rax}(2003 ; 58: 204-11)$, there is an error in the first sentence of the abstract which should read "Proinflammatory leukotrienes, which are not completely inhibited by inhaled corticosteroids, may contribute to asthmatic problems". The publishers apologise for this error. 